\title{
Photocatalytic Dehydrogenative Lactonization of 2-Arylbenzoic Acids
}

\author{
Nieves P. Ramirez, ${ }^{\dagger}$ Irene Bosque, ${ }^{\dagger}$ Jose C. Gonzalez-Gomez* \\ Departamento de Química Orgánica, Facultad de Ciencias and Instituto de Síntesis Orgánica (ISO), Universidad de Alicante, \\ Apdo. 99, 03080 Alicante, Spain.
}

Supporting Information Placeholder

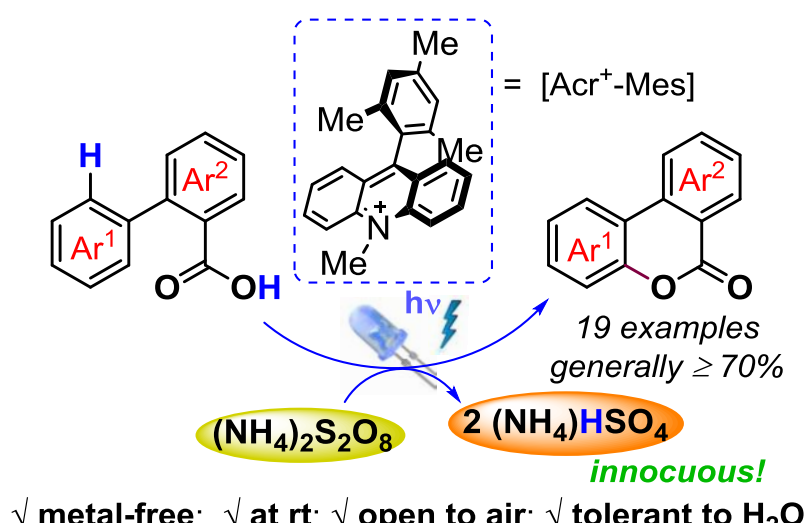

ABSTRACT: A metal-free dehydrogenative lactonization of 2-arylbenzoic acids at room temperature was developed. This work
illustrates the first application of visible-light photoredox catalysis in the preparation of benzo-3,4-coumarins, an important struc-
tural motif in bioactive molecules. The combination of photocatalyst [Acr ${ }^{+}$-Mes] with $\left(\mathrm{NH}_{4}\right)_{2} \mathrm{~S}_{2} \mathrm{O}_{8}$ as terminal oxidant provides an
economical and environmentally benign entry to different substituted benzocoumarins. Preliminary mechanistic studies suggest that
this reaction most likely occurs through a homolytic aromatic substitution pathway.

Benzo-3,4-coumarins derivatives are widely found in natural bioactive compounds, ${ }^{1}$ as well as key intermediates in the synthesis of natural products, ${ }^{2}$ including some examples with axial chirality. ${ }^{3}$ Recently, these molecules have also found interesting applications in material science. ${ }^{4}$ The diverse applications of benzocoumarins make them ideal targets to develop novel efficient methods for their preparation.

Carboxylic acids are readily available and versatile starting materials. ${ }^{5}$ Accordingly, the dehydrogenative lactonization of 2-arylbenzoic acids has emerged as a very attractive approach to prepare benzo-3,4-benzocoumarins. Stoichiometric toxic reactants ${ }^{6}$ as well as UV light ${ }^{7}$ have been used with this purpose, limiting the actual applicability of these methodologies. More recently some metal catalyzed procedures have been developed to enable this $\mathrm{C}-\mathrm{H}$ functionalization/C-O bond formation (Scheme 1, path A). Most of these procedures make use of transition metals such as palladium ${ }^{8}$ or copper based catalysts $^{9}$ and the large HOMO-LUMO energy gap for these reactions ${ }^{10}$ is reflected in reaction temperatures above $75{ }^{\circ} \mathrm{C}$. Very recently, a silver-catalyzed procedure has been reported for this transformation at room temperature, most likely via SET oxidation-radical cyclization. ${ }^{11}$ Also very recently, the first organocatalyzed procedure that enables this transformation at room temperature was developed, avoiding the use of toxic and expensive transition metal catalysts (Scheme 1, path B). ${ }^{12}$ In this context, we describe herein the first organo- catalyzed dehydrogenative lactonization of 2-arylbenzoic acids promoted by visible-light. ${ }^{13}$

Scheme 1. Catalytic Dehydrogenative Lactonization of 2Arylbenzoic Acids

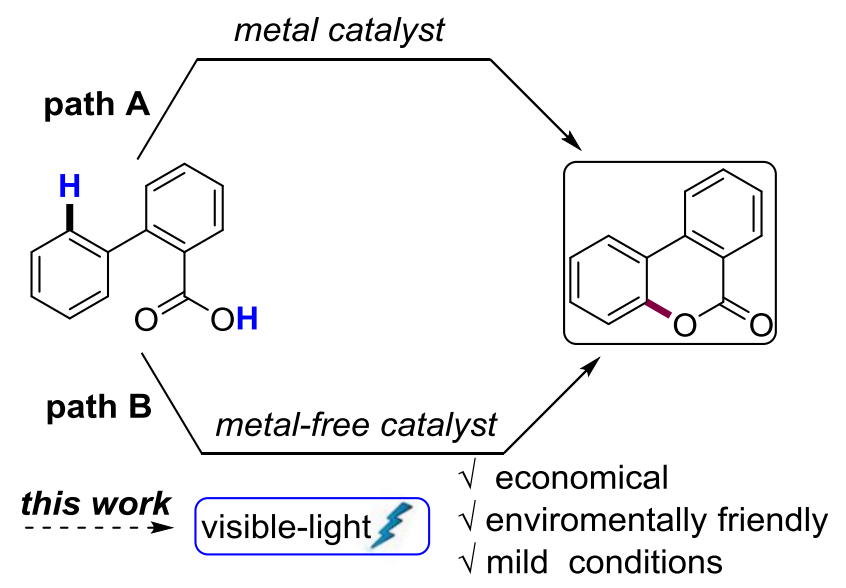

Photocatalytic decarboxylation of carboxylic acids promoted by visible light, via carboxyl radicals, has recently emerged as a powerful synthetic tool. ${ }^{14}$ Given that decarboxylation of aroyloxy radicals is slower that their aliphatic homologues, ${ }^{15}$ decarboxylation of aroyc acids usually requires temperatures 
above $100{ }^{\circ} \mathrm{C} .{ }^{16}$ We thus reasoned that a photocatalytic oxidation of 2-arylbenzoic acids at room temperature, would provide benzoyloxy radicals that could be trapped by the aryl substituent, which after subsequent further oxidation, would lead to benzo-3,4-coumarins. For this transformation we selected the 9-mesityl-10-methylacridinium perchlorate ([AcrMes $\left.] \mathrm{ClO}_{4}\right),{ }^{17}$ one of the strongest oxidants in the excited state upon irradiation with visible light, among organic photocatalysts. The triplet state, with a microsecond lifetime, is generally proposed as the reactive specie in most oxidative transformations. However, the exact nature of the oxidant and its reduction potential is still a matter of debate $\left(\mathrm{E}_{1 / 2}^{\text {red }}=+1.88\right.$ $\mathrm{V}^{18}$ or $1.45 \mathrm{~V}^{19}$ vs SCE). Recent studies have shown that substrates with reduction potentials over $+1.88 \mathrm{~V}$ can also be oxidized with $\left[\mathrm{Acr}^{+}-\mathrm{Mes}\right]^{*}$, most likely through a short-lived singlet state $\left(\mathrm{E}_{1 / 2}{ }^{\text {red }}=+2.08 \mathrm{~V}\right.$ vs SCE$) .{ }^{20}$ Regardless the exact nature of the catalytically active specie, the [Acr $\left.{ }^{+}-\mathrm{Mes}\right]$ has recently proved to be useful for the photocatalytic decarboxylation of aliphatic acids. ${ }^{21}$

\section{Table 1: Reaction Optimization}<smiles>[X]c1ccc(-c2ccccc2C(=O)O)c([X])c1</smiles>

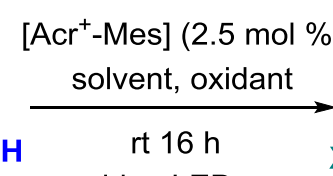
blue LEDs

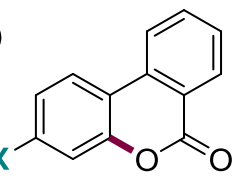

2a: $X=H$

2b: $X=F$

2c: $X=O M e$

\begin{tabular}{|c|c|c|c|c|}
\hline $1(X)$ & entry & solvent $^{\mathrm{a}}$ & oxidant (equiv) & yield $^{\mathrm{b}}$ \\
\hline \multirow{3}{*}{$\begin{array}{l}\mathbf{1 a} \\
(\mathrm{H})\end{array}$} & 1 & A & $\operatorname{air}(1 \mathrm{~atm})^{\mathrm{c}}$ & $70 \%(60 \%)^{\mathrm{d}}$ \\
\hline & 2 & A & $\mathrm{O}_{2}(1 \mathrm{~atm})$ & $60 \%$ \\
\hline & 3 & A & air (1 atm) & $82 \%{ }^{\mathrm{e}}$ \\
\hline \multirow{4}{*}{$\begin{array}{l}\mathbf{1 b} \\
(\mathrm{F})\end{array}$} & 4 & $\mathrm{~A}$ & air $(1 \mathrm{~atm})$ & $45 \%$ \\
\hline & 5 & A & $t$-BuOOH (1) & $73 \%$ \\
\hline & 6 & A & AcOOH (1) & $66 \%$ \\
\hline & 7 & $\mathrm{~B}$ & $\left(\mathrm{NH}_{4}\right)_{2} \mathrm{~S}_{2} \mathrm{O}_{8}(1.2)$ & $\mathbf{7 0 \%}$ \\
\hline \multirow{5}{*}{$\begin{array}{l}\text { 1c } \\
(\mathrm{OMe})\end{array}$} & 8 & A & air $(1 \mathrm{~atm})$ & n.d. ${ }^{\mathrm{f}}$ \\
\hline & 9 & A & $t$-BuOOH (1) & $<10 \%$ \\
\hline & 10 & A & AcOOH (1) & $<10 \%$ \\
\hline & 11 & B & $\left(\mathrm{NH}_{4}\right)_{2} \mathrm{~S}_{2} \mathrm{O}_{8}(1.2)$ & $46 \%$ \\
\hline & 12 & B & $\left(\mathrm{NH}_{4}\right)_{2} \mathrm{~S}_{2} \mathrm{O}_{8}(3)$ & $73 \%$ \\
\hline
\end{tabular}

a A: 1:1 DCE/CH CN; B: 4:1 CH CN/H O. b Isolated yields at $0.2 \mathrm{mmol}$ scale.c The reaction was opened to air via a needle. d At 2 mmol scale, after $48 \mathrm{~h}$. e The reaction was irradiated with sunlight over $8 \mathrm{~h}$, without stirring, see Supporting Information. f Not detected after $48 \mathrm{~h}$.

We were pleased to find that the dehydrogenative lactonization of 2-phenylbenzoic acid (1a) took placed efficiently upon irradiation with blue LEDs at room temperature, using [AcrMes $] \mathrm{ClO}_{4}$ as photocatalyst and air as terminal oxidant (Table 1 , entry 1). ${ }^{22}$ The reaction worked with similar efficiency in DCE, $\mathrm{CH}_{3} \mathrm{CN}$ or mixture of these two solvents; while other solvents (e.g. $\mathrm{CHCl}_{3}$, EtOAc or DMF) were less suitable. The replacement of air for an oxygen atmosphere, as well as the addition of basic 2,6-lutidine (not shown in Table 1), did not improve the results. When the reaction was scaled up to 2 mmol, took longer $(48 \mathrm{~h})$ and the isolated yield was slightly slower $(60 \%) .^{23}$ Remarkably, compound $2 a$ was obtained in $82 \%$ isolated yield after $8 \mathrm{~h}$ of sunlight irradiation in an open tube without stirring (entry 3). Unfortunately, when 2arylbenzoic acids $\mathbf{1 b}$ and $\mathbf{1 c}$, with different electronic demands, were submitted to the conditions described in entry 1 , only $45 \%$ yield was obtained for compound $\mathbf{2 b}$ and no reaction was observed for 1c. After examined different oxidants and conditions (entries 5, 6, 9 and 10), we found that $\left(\mathrm{NH}_{4}\right)_{2} \mathrm{~S}_{2} \mathrm{O}_{8}$ was a competent oxidant for both substrates. Although about 1 equivalent was sufficient for both substrates (entries 7 and 11), the addition of 3 equivalents of this oxidant accelerate the reaction of 1c (entry 12). It is worth noting that the reactions are run in organic/aqueous solvent mixtures, which increase the solubility of $\left(\mathrm{NH}_{4}\right)_{2} \mathrm{~S}_{2} \mathrm{O}_{8}$, and can be run in open flasks. Moreover, this stoichiometric oxidant is cheap, non-toxic, easily removed from reaction mixtures and generates innocuous by-products upon reduction (most likely $\mathrm{HSO}_{4}^{-}$).

\section{Scheme 2. Substrate Scope}
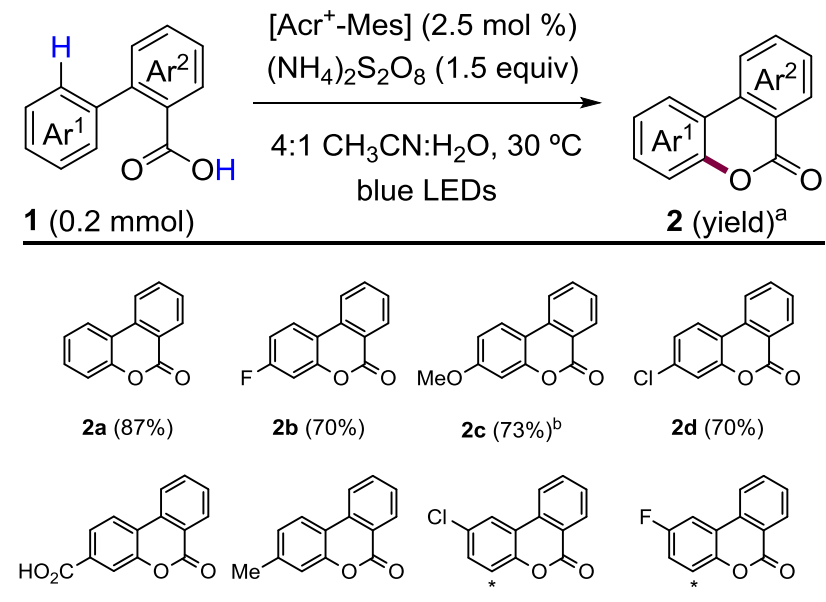

2c $(73 \%)^{b}$

2d $(70 \%)$

2 e $(53 \%)^{\mathrm{c}}$

$2 f(76 \%)^{d}$
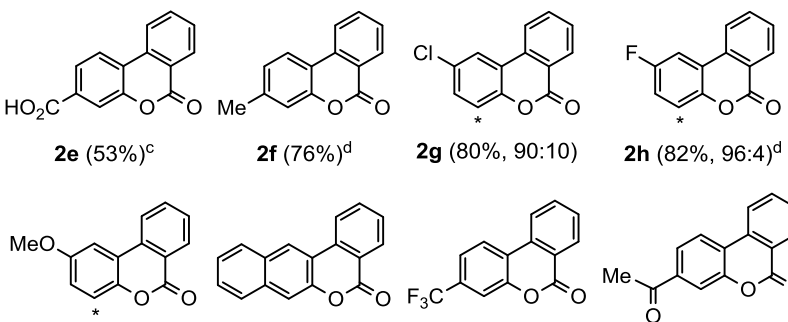

$\mathbf{2 g}(80 \%, 90: 10)$

2h $(82 \%, 96: 4)^{\text {d }}$
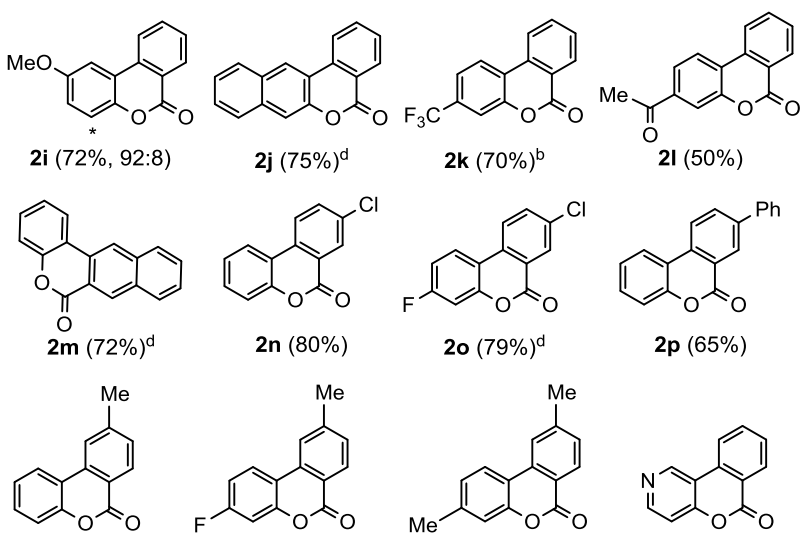

$2 \mathbf{q}(71 \%)^{\mathrm{d}}$

$2 r(59 \%)^{d}$

2s $(77 \%)^{d}$

2t $(0 \%)^{b}$

${ }^{\mathrm{a}}$ Isolated yields of reactions run on $0.2 \mathrm{mmol}$-scale until complete conversion by TLC (see details in SI). ${ }^{\text {b }} 3$ equiv of $\left(\mathrm{NH}_{4}\right)_{2} \mathrm{~S}_{2} \mathrm{O}_{8}$ were used. ${ }^{\mathrm{c}}$ Air $(1 \mathrm{~atm})$ was used as oxidant and a 1:1:1 $\mathrm{CH}_{3} \mathrm{CN} / \mathrm{DCE} / \mathrm{MeOH}$ mixture. ${ }^{\mathrm{d}} 4: 1 \mathrm{DCE} / \mathrm{H}_{2} \mathrm{O}$. *Minor regioisomer. 
To evaluate the scope of the reaction, a variety of 2arylbenzoic acids were submitted to the optimized reaction conditions. Different 4'-substituted acids bearing electrondonor or electron-withdrawing groups furnished the corresponding benzocoumarins in good yields (Scheme 2). Generally, 1.5 equivalents of $\left(\mathrm{NH}_{4}\right)_{2} \mathrm{~S}_{2} \mathrm{O}_{8}$ were used, although 3 equivalents were necessary for the less reactive substrates $(\mathbf{2 c}$ and 2k). Although most reaction were run in $\mathrm{CH}_{3} \mathrm{CN} / \mathrm{H}_{2} \mathrm{O}$, in some cases better results were obtained in a DCE/ $\mathrm{H}_{2} \mathrm{O}$ mixture $(\mathbf{2 f}$, 2h, 2j, 2m, 2o, 2q, 2r, 2s). Presumably, in DCE/ $\mathrm{H}_{2} \mathrm{O}$ overoxidation is minimized due to a lower concentration of the stoichiometric oxidant in the organic phase. In the case of diacid 1e, an organic solvent mixture was used to dissolve the substrate and the desired reaction took place in 53\% yield using air as terminal oxidant. For 3'-substituted acids, the corresponding benzocoumarins $(\mathbf{2} \mathbf{g}, \mathbf{2 h}, \mathbf{2} \mathbf{i})$ were obtained in good yields and with regioselectivities ranging from 90:10 to 96:4. It is worth mentioning that the regioselectivity obtained for benzocoumarin $\mathbf{2 i}$ under our conditions (92:8) is higher than the one reported for this compound using a copper catalyst at $75-85^{\circ} \mathrm{C}^{9}$ and similar to the one obtained with a silver catalyst at room temperature. ${ }^{11}$ Unfortunately, 2-(3`-pyridinyl)benzoic acid (1t) did not react under the established reaction conditions. Other heterocyclic substrates have not been systematically examined yet.

To gain insight into the reaction pathway, some control experiments and preliminary mechanistic studies were carried out (Scheme 3). When substrate 1d was submitted to the reaction conditions described in Scheme 2, but in the absence of light or photocatalyst, as well as in the presence of TEMPO (1 equiv), the reaction was completely inhibited $(<5 \%)$. These experiments suggest a photoredox process where radicals are likely involved. We also determined the intermolecular kinetic isotopic effect [see Supporting Information (SI) for details] by measuring the individual initial rates of $\mathbf{1 a}$ and $\mathbf{1 a}-\mathbf{D}_{\mathbf{5}}\left(\mathrm{k}_{\mathrm{H}} / \mathrm{k}_{\mathrm{D}}=\right.$ $1.3)$ and by competition experiments $\left(\mathrm{k}_{\mathrm{H}} / \mathrm{k}_{\mathrm{D}}=1.1\right)$. These results suggest that the $\mathrm{C}-\mathrm{H}$ bond cleavage might not be the turnover-determining step in the catalytic process. ${ }^{24}$

Based on our preliminary mechanistic investigations, we tentatively proposed a reaction pathway (Scheme 4) where the activated photocatalyst might generate the benzoyloxy radical I' via single electron transfer (SET). The cyclization should follow a 6 -endo-trig approach ${ }^{25}$ to give intermediate $\mathbf{I I}^{\mathbf{2}}$, which is finally oxidized to product $\mathbf{2}$ via hydrogen atom abstraction (HAT) or SET/deprotonation processes. The catalyst turn-over would be possible by oxidation with persulfate anion (or atmospheric oxygen for $\mathbf{2 a}$ and $\mathbf{2 e}$ ), generating the sulfate radical-anion $\left[\mathrm{SO}_{4}{ }^{-}\right]$that can still act as oxidant in the final aromatization step or in the turn-over of the catalyst. This is in line with the observation that only 1 equiv of persulfate is required for most substrates. Based on our kinetic isotopic experiments, and on the high oxidation capacity of the excited photocatalyst that should favor a highly exergonic and fast SET process to generate $\mathbf{I}^{\bullet}$, we speculate that the cyclization is the turnover-determining step. For electron-rich substrates, a different pathway based on the formation of aromatic radicalcations seems also plausible, but the regioselectivity observed for substrate $\mathbf{2} \mathbf{i}$ is not in accordance with this proposal (see SI for more details). Other mechanisms might also come into play.
Scheme 3: Preliminary Mechanistic Investigations

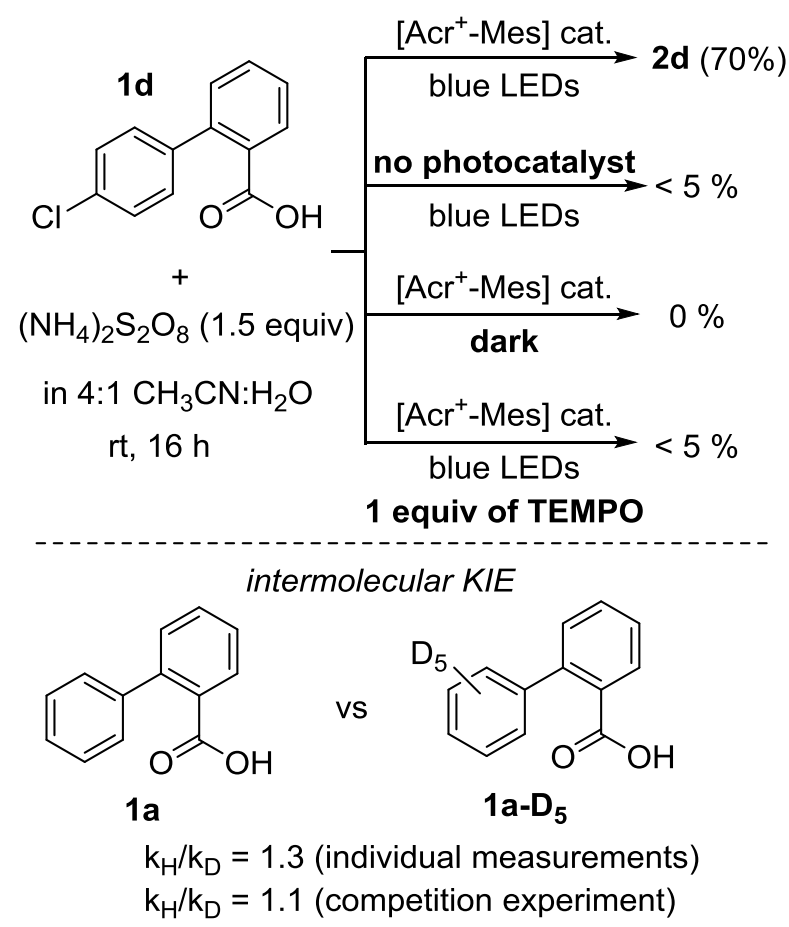

Scheme 4. Plausible Mechanism

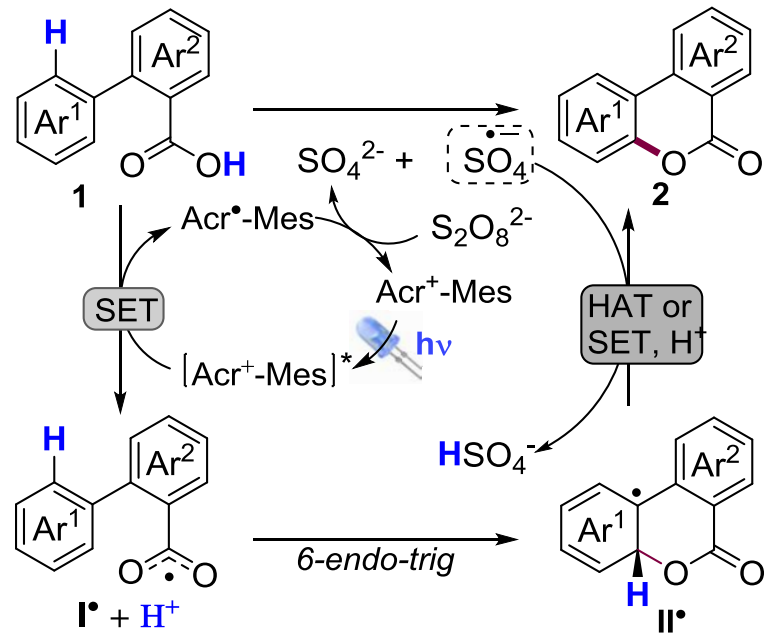

To gather more information on the reaction pathway, lactone $\mathbf{2 a}$ was opened in the presence of MeI and $\mathrm{KOH}^{9 \mathrm{a}}$, and the obtained ester was hydrolyzed (Scheme 5). Acid 1u was submitted to the photocatalytic dehydrogenative lactonization and compound 2a was obtained as a single product in excellent yield. This result is in accordance with the homolytic aromatic substitution pathway depicted in Scheme 4, and other authors have observed similar results using other different oxidants for 2 -substituted-2-arylbenzoic acids. ${ }^{26}$ The preferred addition at the ipso-position should result from a kinetic and/or thermodynamic control at the cyclization step, presumably due to steric hindrance between $\mathrm{OMe}$ and $\mathrm{H}_{10}$ in $\mathbf{2 u}$.

In summary, we have developed a visible-light photocatalytic dehydrogenative lactonization of 2-arylbenzoic acids. This 
method provides a general and convenient access to benzo3,4-coumarins under mild (room temperature), robust (tolerant to water and air) and environmentally friendly (benign reagents and residues) conditions.

Scheme 5. Lactone Ring-Opening of 2a and Ring-Closing under Photocatalysis<smiles>O=c1oc2ccccc2c2ccccc12</smiles>

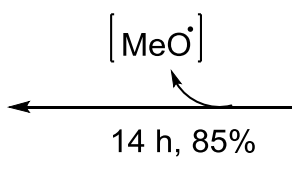

$2 a$<smiles>CO[C@]12C=CC=CC1c1ccccc1C(=O)O2</smiles>

$84 \% \mid \begin{aligned} & \text { 1. } \mathrm{KOH}, \mathrm{Mel}, 70^{\circ} \mathrm{C} \\ & \text { 2. } 1 \mathrm{M} \mathrm{NaOH}, 70^{\circ} \mathrm{C}\end{aligned}$<smiles>COc1ccccc1-c1ccccc1C(=O)O</smiles>

[Acr $\left.{ }^{+}-\mathrm{Mes}\right](2.5 \mathrm{~mol} \%)$ $\left(\mathrm{NH}_{4}\right)_{2} \mathrm{~S}_{2} \mathrm{O}_{8}$ (3 equiv) $4: 1 \mathrm{CH}_{3} \mathrm{CN} / \mathrm{H}_{2} \mathrm{O}, \mathrm{rt}$ blue LEDs $1 \mathrm{u}$
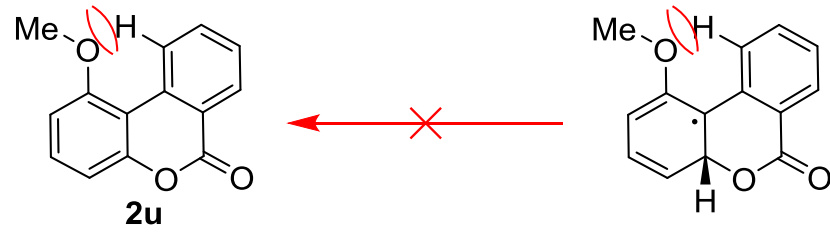

\section{ASSOCIATED CONTENT}

\section{Supporting Information}

Experimental procedures, characterization data and NMR spectra. This material is available free of charge via the Internet at http://pubs.acs.org.

\section{AUTHOR INFORMATION}

\section{Corresponding Author}

*E-mail: josecarlos.gonzalez@ua.es

\section{Author Contributions}

$\uparrow$ These authors contributed equally

\section{Notes}

The authors declare no competing financial interest.

\section{ACKNOWLEDGMENTS}

We thank the Spanish Ministerio de Ciencia e Innovación (CTQ2011-24165) for financial support. I. B. acknowledges the Generalitat Valenciana for a postdoctoral fellowship (ACIF/2011/159).

\section{REFERENCES}

(1) Selected examples: (a) Alo, B. I.; Kandil, A.; Patil, P. A.; Sharp, M. J.; Siddiqui, M. A.; Snieckus, V. J. Org. Chem. 1991, 56, 3763. (b) Abe, H.; Nishioka, K.; Takeda, S.; Arai, M.; Takeuchi, Y.; Harayama, T. Tetrahedron Lett. 2005, 46, 3197. (c) Koch, K.; Podlech, J.; Pfeiffer, E.; Metzler, M. J. Org. Chem. 2005, 70, 3275. (d) Tibrewal, N.; Pahari, P.; Wang, G.; Kharel, M. K.; Morris, C.;
Downey, T.; Hou, Y.; Bugni, T. S.; Rohr, J.; J. Am. Chem. Soc. 2012, 134, 18181.

(2) For recent examples: (a) Li, Y.; Ding, Y.-J.; Wang, J.-Y.; Su, Y.-M.; Wang, X.-S. Org. Lett. 2013, 15, 2574. (b) Moschitto, M. J. ; Anthony, D. R.; Lewis, C. A.; J. Org. Chem. 2015, 80, 3339.

(3) For excellent reviews: (a) Bringmann, G.; Menche, D. Acc. Chem. Res. 2001, 34, 615. (b) Bringmann, G.; Gulder, T.; Gulder, T. A. M.; Breuning, M. Chem. Rev. 2011, 111, 563.

(4) (a) Fletcher, S. P.; Dumur, F.; Pollard, M. M.; Feringa, B. L. Science 2005, 310, 80. (b) Yang, C.; Hsia, T.; Chen, C.; Lai, C.; Liu, R. Org. Lett. 2008, 10, 4069.

(5) Gooßen, L. J.; Rodríguez, N.; Gooßen, K. Angew. Chem. Int Ed. 2008, 47, 3100 .

(6) (a) Kenner, G. W.; Murray, M. A.; Tylor, C. M. B. Tetrahedron 1957, 1, 259. (b) Davies, D.; Waring, C. Chem. Commun. 1965, 263.

(7) (a) Togo, H.; Muraki, T.; Yokoyama, M. Tetrahedron Lett. 1995, 36, 7089. (b) Furuyama, S.; Togo, H. Synlett 2010, 2325.

(8) Li, Y.; Ding, Y.-J.; Wang, J.-Y.; Su, Y.-M.; Wang, X.-S. Org. Lett. 2013, 15, 2574

(9) (a) Wang, Y.; Gulevich, A. V.; Gevorgyan, V. Chem. Eur. J. 2013, 19, 15836. (b) Gallardo-Donaire, J.; Martin, R. J. Am. Chem. Soc. 2013, 135, 9350.

(10) Vedernikov, A. N. Top. Organomet. Chem. 2010, 31, 101.

(11) Dai, J.-J.; Xu, W.-T.; Wu, Y.-D.; Zhang, W.-M.; Gong, Y.; He, X.-P.; Zhang, X.-Q.; Xu, H.-J. J. Org. Chem. 2015, 80, 911.

(12) Wang, X.; Gallardo-Donaire, J.; Martin, R. Angew. Chem. Int. Ed. 2014, 53, 11084.

(13) For seminal contributions on visible light photocatalysis: (a) Nicewicz, D.; MacMillan, D. W. C. Science 2008, 32, 77. (b) Ischay, M. A.; Anzovino, M. E.; Du, J.; Yoon, T. P. J. Am. Chem. Soc. 2008 , 130, 12886. (c) Narayanam, J. M. R.; Tucker, J. W.; Stephenson, C. R. J. J. Am. Chem. Soc. 2009, 131, 8756. (d) Prier, C. K.; Rankic, D. A.; MacMillan, D. W. C. Chem. Rev. 2013, 113, 5322. (e) Schultz, D. M.; Yoon, T. P. Science 2014, 343, 6174. (f) Beatty, J. W.; Stephenson, C. R. J. Acc. Chem. Res. 2015, 48, 1474.

(14) For representative examples, see: (a) Nakayama, H.; Itoh, A. Tetrahedron Lett. 2008, 49, 2792. (b) Miyake, Y.; Nakajima, K.; Nishibayashi, Y. Chem. Commun. 2013, 49, 7854. (c) Zuo, Z.; MacMillan, D. W. C. J. Am. Chem. Soc. 2014, 136, 5257. (d) Noble, A.; McCarver, S. J.; MacMillan, D. W. C. J. Am. Chem. Soc. 2015, 137, 624. (e) Ventre, S.; Petronijevic, F. R.; MacMillan, D. W. C. J. Am. Chem. Soc. 2015, 137, 5654.

(15) (a) Barton, D. H. R.; Lacher, B.; Zard, S. Z. Tetrahedron 1987, 43, 4321. (b) Chateauneuf, J.; Lusztyk, J.; Ingold, K. U. J. Am. Chem. Soc. 1988, 110, 2886. (c) Kochi, J. K.; Bockman, T. M.; Hubig, S. M. J. Org. Chem. 1997, 62, 2210.

(16) (a) Seo, S.; Slater, M.; Greaney, M. F. Org. Lett. 2012, 14 2650. (b) Seo, S.; Taylor, J. B.; Greaney, M. F. Chem. Commun. 2012, 48, 8270, and references therein.

(17) Fukuzumi, S.; Kotani, H.; Ohkubo, K.; Ogo, S.; Tkachenko, N. V.; Lemmetyinen, H. J. Am. Chem. Soc. 2004, 126, 1600.

(18) For recent reviews: (a) Fukuzumi, S.; Ohkubo, K.; Suenobu, T. Acc. Chem. Res. 2014, 47, 1455. (b) Fukuzumi, S.; Ohkubo, K. Org. Biomol. Chem., 2014, 12, 6059. (c) Nicewicz, D. A.; Hamilton, D. S. Synlett 2014, 25, 1191.

(19) Benniston, A. C.; Harriman, A.; Li, P.; Rostron, J. P.; van Ramesdonk, H. J.; Groeneveld, M. M.; Zhang, H.; Verhoeven, J. W. J. Am. Chem. Soc. 2005, 127, 16054.

(20) Romero, N. A.; Nicewicz, D. A. J. Am. Chem. Soc. 2014, 136, 17024.

(21) Cassani, C.; Bergonzini, G.; Wallentin, C.-J. Org. Lett. 2014, 16,4228 .

(22) The internal temperature of the irradiated reaction mixture was found to be in the range $30-35^{\circ} \mathrm{C}$.

(23) The use of flow techniques is a well-established approach to solve scale-up problems in visible-light photoredox catalysis, see for example: Garlets, Z. J.; Nguyen, J. D.; Stephenson, C. R. J. Isr. J. Chem. 2014, 54, 351, and references therein. 
(24) Simmons, E. M.; Hartwig, J. F. Angew. Chem. Int. Ed. 2012, 51,3066 .

(25) It is known that $\alpha$-carbonyl radicals prefer a 6-endo-trig addition: (a) Curran, D. P.; Chang, C.-T.; J. Org. Chem. 1989, 54, 3140

(b) Broeker, J. L.; Houk, K. N. J. Org. Chem. 1991, 56, 3651.
(26) Togo, H.; Muraki, T.; Yokoyama, M. Tetrahedron Lett. 1995, 36,7089 . 